\title{
Medicated Vaginal Tampon Dosage Form
}

National Cancer Institute

\section{Source}

National Cancer Institute. Medicated Vaginal Tampon Dosage Form. NCI Thesaurus.

Code C149655.

Solid single-dose preparation consisting of a suitable material impregnated with active substance(s) intended to be inserted in the vagina for a limited period of time. 